\title{
Análise dos Resultados de um Estudo de Caso Aplicando Pensamento Computacional no Ensino Fundamental com Foco na Produção de Algoritmos
}

\author{
Luciana P. de Araújo Kohler, Mauro M. Mattos, Maurício Capobianco Lopes, \\ Leonardo Fronza, Heitor Ugarte Calvet da Silveira, Guilherme Fibrantz, \\ Vítor Lourenço da Rosa, Lucas Hong Lae Son \\ ${ }^{1}$ Laboratório de Desenvolvimento e Transferência de Tecnologia - LDTT \\ Universidade Regional de Blumenau - FURB \\ Blumenau - SC - Brasil. \\ $\{$ LPA, mattos, mclopes\}@furb.br
}

\begin{abstract}
The work presents a case study carried out with 93 students from five classes of elementary school in a state school, in order to identify whether the practice with activity mediated by mobile technology that stimulates the development of skills in computational thinking positively influences the resolution process everyday problem. After some analysis comparing the exercises performed before the activities and after the activities, as well as the comparison of the results of the classes involved, it is possible to state that the activities help in resolution process problem.
\end{abstract}

Resumo. O presente artigo tem por objetivo analisar o potencial de uma prática mediada por tecnologia com pensamento computacional. O estudo de caso foi realizado com 93 alunos de 5 turmas do ensino fundamental de uma escola Estadual com o objetivo de identificar se a prática influencia positivamente no processo da resolução de problemas cotidianos. Após algumas análises comparando exercícios realizados antes das atividades e após as atividades, bem como comparando resultados das turmas envolvidas, consegue-se afirmar que as atividades auxiliam na melhoria da resolução de problemas cotidianos.

\section{Introdução}

Conforme [Raabe et al. 2017], "a computação é uma ciência que investiga a resolução de problemas, proporciona a criação de um mundo novo e muda radicalmente o comportamento da sociedade". A necessidade em resolver problemas está presente na vida do ser humano desde o seu nascimento, uma vez que necessita encontrar uma forma de se alimentar e interagir com os familiares, por exemplo. Essa necessidade vem crescendo à medida em que o indivíduo evolui, de modo que alguns possuem mais dificuldades em compreender e raciocinar.

Nessa linha, o termo Pensamento Computacional (PC), introduzido por Wing [Wing 2006], representa uma forma de estruturar logicamente o pensamento para a solução de problemas utilizando como características a decomposição do problema em partes menores, a identificação de padrões e construção de algoritmos que não necessariamente dependem de computadores para serem executados. Portanto, desenvolver habilidades em 
PC não significa aprender a programar, mas possibilita o desenvolvimento de habilidades que podem ajudar as crianças na resolução de problemas em todas as áreas da vida, seja de maneira individual ou colaborativa [Zanetti et al. 2016].

O pensamento computacional se manifesta desde a infância e consiste em um processo mental intuitivo que se ativa para encontrar respostas inovadoras por meio de raciocínio lógico [Stephenson et al. 2012, Nunes 2011, Wing 2006, Zanetti et al. 2016]. Associando pensamento crítico e fundamentos da computação, esse conceito introduz uma nova abordagem de ensino voltada ao desenvolvimento de habilidades de abstração [Brackmann 2017].

O Pensamento Computacional é abordado na Base Nacional Comum Curricular (BNCC) e se constitui em um documento normativo que visa definir um conjunto de aprendizagem essencial que os estudantes brasileiros devem desenvolver na sua vida escolar, independente da modalidade e etapa que estejam, tornando a educação mais igualitária sem desrespeitar as singularidades de cada região [Brasil 2017].

Neste contexto a Sociedade Brasileira de Computação (SBC) definiu diretrizes para o ensino da computação na Educação Básica [SBC 2019]. A partir dessas diretrizes, o Centro de Inovação para a Educação Brasileira (CIEB) sistematizou um currículo de referência que pode ser aplicado na educação infantil, ensino fundamental e ensino médio [CIEB 2018].

Uma revisão sistemática da literatura feita por [Avila et al. 2017] identificou que a maioria dos trabalhos que abordam o Pensamento Computacional refere-se ao pilar de algoritmos, desenvolvendo o pensamento algorítmico e as técnicas de programação. Nessa linha, este artigo tem como ponto de partida o pilar da construção de algoritmos do PC. Assim, o objetivo do presente trabalho é identificar se a prática com atividades mediadas por tecnologia móvel que utilizam recursos para estimular o desenvolvimento de habilidades em PC influenciam positivamente no processo de resolução de problemas cotidianos.

O artigo está organizado da seguinte forma. A seção 2 apresenta e descreve os métodos e metodologia utilizada nesta pesquisa, sendo uma pesquisa descritiva fomentada por um estudo de campo. A seção 3 discute os resultados alcançados, após a aplicação metodológica. Por fim, a seção 4 conclui este trabalho.

\section{Métodos}

Em busca de alcançar o objetivo estabelecido, foram realizados nove (9) encontros de uma hora-aula cada com cinco (5) turmas do Ensino Fundamental I no ano de 2019, sendo as turmas de primeiro ao quinto ano de uma escola Estadual, totalizando 45 encontros com a participação de 93 alunos. Antes dos encontros, realizou-se uma formação com essas professoras para que conhecessem as atividades a serem trabalhadas. Essa formação aconteceu em dois dias com uma (1) hora de duração cada. Em cada um dos encontros em sala de aula, participaram a professora regente de turma, seus alunos (sujeitos da pesquisa), dois alunos bolsistas do curso de Ciência da Computação e uma professora do Departamento de Sistemas e Computação.

Desses nove encontros, em três deles utilizou-se computação desplugada com diversas atividades. Nos demais, foi aplicado um jogo, denominado Furbot, que auxilia no 
desenvolvimento de habilidades em PC. Ambos serão detalhados na próxima seção.

Segundo [Gil 2002] e [Wazlawick 2010] a pesquisa em questão é classificada como aplicada, tendo como verdade inicial que os exercícios que envolvem algoritmos influenciam positivamente no desenvolvimento do raciocínio lógico. É uma pesquisa descritiva, sendo os alunos participantes dos encontros os objetos de estudo. Ainda, faz-se uma análise da situação-problema comparando a situação inicial (no primeiro encontro), com a situação final (no nono encontro). Também é uma pesquisa mista (quali-quantitativa), uma vez que se analisa os alunos por meio de observação direta, porém se utiliza dos dados como número de alunos, algoritmos realizados, problemas resolvidos e série dos alunos para uma análise mais detalhada da situação-problema. Como procedimento a pesquisa se classifica como estudo de campo e utilizou-se tablets e papel para a execução das atividades.

\subsection{Materiais e Atividades Realizadas}

No contexto da computação desplugada foram realizadas três atividades. A primeira atividade foi solicitar aos alunos que escrevessem no papel como eles fazem para sair da sua sala de aula e chegar no refeitório da escola. Essa atividade corresponde à produção do passo a passo de um algoritmo do cotidiano, com o objetivo de identificar o grau de abstração e de decomposição presente em cada criança antes de iniciar as atividades propriamente ditas. Essa será a atividade a ser comparada posteriormente ao nono encontro, para a identificação da situação-problema, em busca do objetivo desta pesquisa.

A segunda atividade foi fornecer um conjunto de cartas embaralhadas com figuras que representam a ação de tomar banho, desde tirar a roupa até se vestir novamente. Nessa atividade os alunos precisam compreender as figuras e posicioná-las em uma sequência logicamente correta, treinando assim a habilidade de composição. A terceira atividade foi um jogo de tabuleiro, no qual utilizando os comandos andarNorte (), andarSul (), andarLeste () e andarOeste () o jogador deve sair de uma posição inicial até chegar em uma posição final a partir de regras pré existentes. Dessa forma, treina-se a composição e, a partir dela, a construção de um algoritmo que representa o caminho percorrido pelo jogador no tabuleiro.

As duas primeiras atividades são feitas individualmente e a terceira em equipes de quatro alunos. Na Figura 2.1 tem-se algumas crianças realizando as atividades. Essas atividades foram descritas detalhadamente em [Kohler et al. 2019].

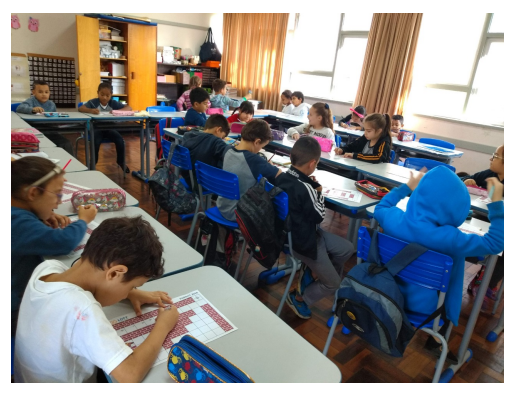

Figura 1. Alunos em atividade de computação desplugada

Já o jogo aplicado tem como objetivo trabalhar as subáreas envolvidas no pensamento computacional de forma digital mantendo o teor lúdico presente nas atividades 
desplugadas. Na prática, o aluno resolverá uma série de desafios intercalados com minijogos. Esses minijogos tanto trabalham habilidades cognitivas quanto conteúdos interdisciplinares, assim como também servem para proporcionar uma descontração logo após o término de um desafio mais longo.

O jogo tem um contexto para justificar o que está sendo trabalhado através de uma história que foi concebida a fim de torná-lo ainda mais lúdico. Assim, na história há uma professora cientista chamada Sam que desenvolveu um robô com o propósito de preservar e proteger a natureza do planeta Terra. Contudo, antes que pudesse terminar este robô, o planeta é invadido por alienígenas com o intuito de dominar a Terra para usarem a seu favor, consumindo todos os seus recursos naturais de forma descontrolada. Ao ficarem sabendo da existência do robô, os alienígenas, chamados de Buggiens, sequestram a professora. Assim, o objetivo do jogador é salvá-la e impedir que a Terra seja dominada. Para fazer isto, o jogador precisará deslocar o robô e sua drone ajudante, denominada S223, por vários cenários, coletando pistas e itens para ajudar na sua jornada. Além de resolver desafios para chegar à próxima etapa. O jogo é dividido em 4 regiões que por sua vez são divididas em 5 fases cada, tendo um total de 20 fases.

Iniciando na região amazônica, representada na Figura 2, o jogador precisará analisar o cenário da fase em que está inserido para encontrar uma pista que indique para onde levaram a professora, sendo esta representada por uma mancha verde em algum ponto do cenário. Na Figura 3, essa mancha aparece no final do caminho na parte inferior direita. O objetivo então, é deslocar o robô até essa pista, evitando os obstáculos presentes no cenário como pedras, árvores, rios, arbustos, entre outros. Para movê-lo, os comandos utilizados são semelhantes aos aplicados no jogo de cartas, sendo eles: andar (acima), andar (abaixo), andar(direita), andar (esquerda). Esses comandos são colocados na área do programa, que se localiza no canto superior direito da Figura 3. Inicialmente, deve-se fazer uso destes comandos para mover o robô através do cenário e chegar na pista da forma mais eficiente possível, constituindo um algoritmo ao fim da fase.

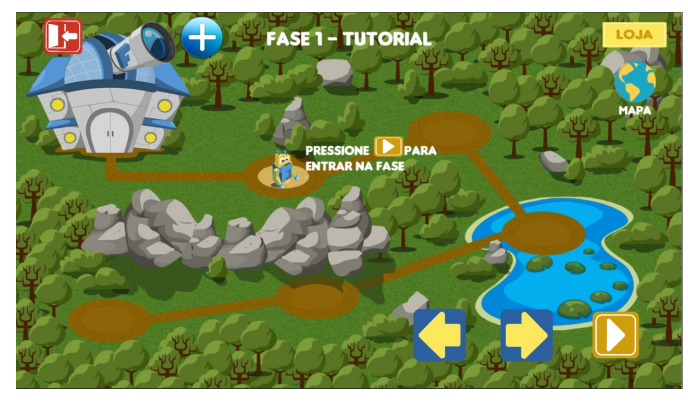

Figura 2. Região amazônica

Entretanto, existem alguns indicadores do robô que são afetados de acordo com as ações do jogador, disponíveis na parte inferior da tela do jogo disponível também na Figura 3. Inicialmente, existe um número limitado de vidas disponíveis, sendo o valor inicial e máximo 3. Caso o jogador perca as 3 vidas, ele terá que reiniciar o jogo da região em que morreu. Estas vidas são consumidas de acordo com os erros cometidos durante o jogo, como por exemplo, mover o robô para dentro de um rio ou lago ou colidir repetidas vezes contra um ou mais obstáculos. Um segundo indicador presente é o de energia, 


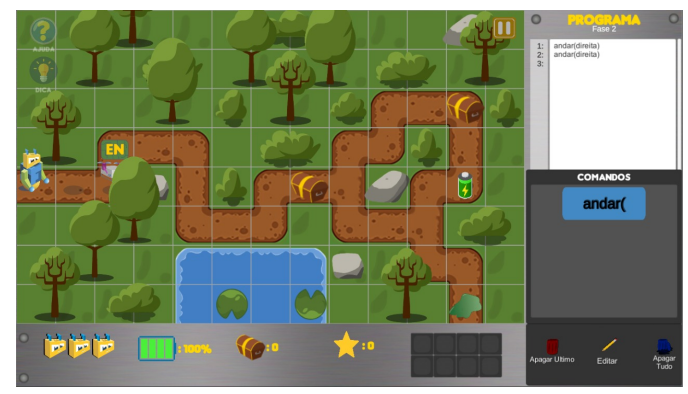

Figura 3. Fase da região amazônica

que é consumida a cada comando executado. A cada passo correto (quando o robô anda pela trilha), a perda de energia é de somente $1 \%$. Caso contrário, a cada movimento são descontados $5 \%$ de energia de um total de $100 \%$. Caso a energia se esgote, o jogador perde uma vida. Além disso, a cada colisão com o cenário são descontados $25 \%$ de energia. Para possibilitar a reposição de vidas e energia existem coletáveis, tanto de vida quanto de energia, que ao passar por cima são concedidos ao jogador.

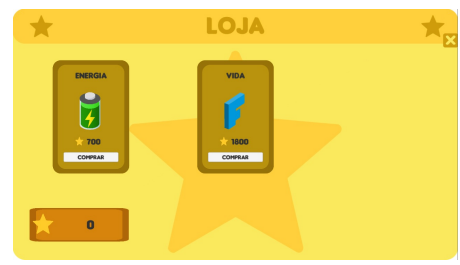

Figura 4. Loja

Também é possível acessar uma loja na tela de seleção de fases para reabastecer estes indicadores utilizando os pontos acumulados pela resolução das fases. Esta loja é ilustrada na Figura 4. Estes pontos são calculados conforme a resolução da fase, representando o desempenho do jogador até o momento. Após a finalização das 5 fases presentes na região amazônica, de acordo com a história do jogo, o robô e a S-223 descobrem que a professora foi levada para o Egito, levando os jogadores para uma nova região com um novo conjunto de cenários e obstáculos diferentes, conforme ilustra a Figura 5.

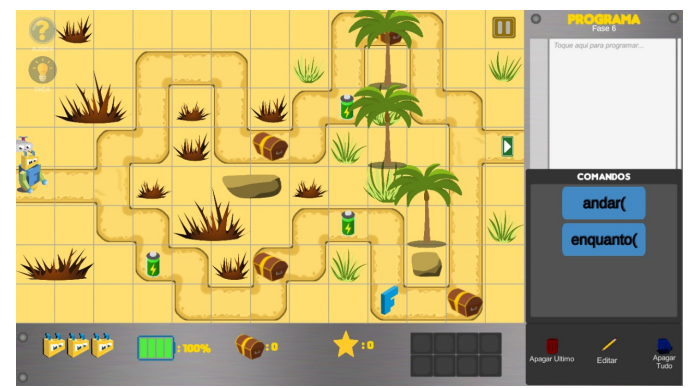

Figura 5. Fase da região do Egito

Nesta nova região é introduzido o comando de repetição enquanto, possibilitando criar laços de repetição a fim de otimizar a escrita de código. Dessa forma, cria-se maneiras de solucionar os cenários propostos e trabalhar habilidades em PC de maneira 
mais aprofundada. Também, intercalando-se com as fases do Egito, um minijogo é apresentado ao finalizá-la. Nesse, o jogador deve reciclar adequadamente os objetos que são despejados pelos alienígenas a fim de reduzir a poluição na região. Além disso, a história conduz os jogadores para dentro das pirâmides, conforme ilustrado na Figura 6, a fim de conseguir mais pistas do rumo dos alienígenas, proporcionando uma nova ambientação e desafios para resolver.

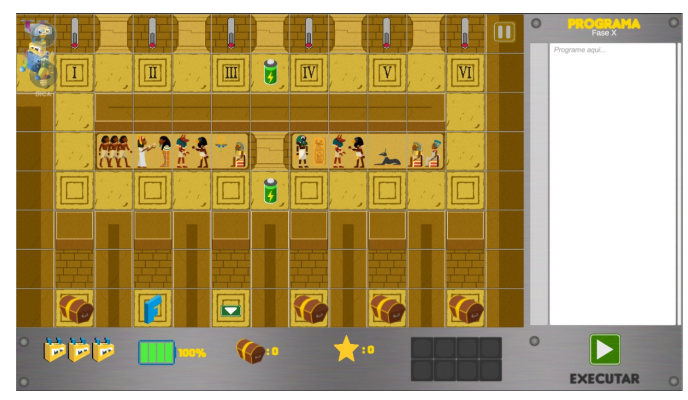

Figura 6. Fase dentro da pirâmide

Enquanto o aluno faz sua progressão no jogo, sempre é possível retornar à tela de seleção de fases para jogar qualquer um dos desafios já resolvidos para praticar ou solucionar de forma mais eficiente cada desafio. Nesta tela, pode-se navegar entre as regiões que já foram desbloqueadas pelo jogador, e quando dentro de uma das regiões, navegar entre as fases que estão disponíveis para jogar. O jogador pode decidir refazer uma fase a fim de melhorar sua pontuação ou praticar os conceitos apresentados.

Tanto as atividades desplugadas quanto o jogo foram desenvolvidos pela equipe do projeto, sendo um projeto de extensão da Universidade. Participaram da produção dos materiais acadêmicos e professores dos cursos de Ciência da Computação, Sistemas de Informação, Publicidade e Propaganda, Design e Pedagogia. Esse projeto existe como projeto de extensão há 4 anos. Contudo, para se desenvolver o jogo, utilizou-se como inspiração um framework desenvolvido na Universidade que já é utilizado há mais de 10 anos com alunos de graduação. $\mathrm{O}$ jogo em questão foi desenvolvido na plataforma Unity e todas as imagens utilizadas foram desenvolvidas pela própria equipe, com exceção do personagem principal que foi desenhado pleo Belli Studio.

Dos nove encontros realizados, nos dois primeiros e no último aplicou-se as atividades deplugadas e nos demais seis encontros, os alunos jogaram o jogo que trabalha as habilidades de pensamento computacional de forma gamificada.

Optou-se por utilizar as mesmas atividades em todas as turmas de $1^{\circ}$ ao $5^{\circ}$ ano, pois, embora saiba-se que o grau de dificuldade entre cada uma das idades é diferenciado, as atividades podem ser adaptadas para as diferentes idades. Por exemplo, para o primeiro ano, as atividades desplugadas foram realizadas por meio de imagens representativas e foram mediadas pela professora regente da turma. Para o segundo ano, as atividades foram realizadas também por meio de imagens representativas, mas não houve a mediação da professora regente. Do terceiro ao quinto ano, os alunos trabalharam com os jogos completos formados pela parte visual (imagem) e escrita, porém, quanto maior a idade dos alunos, mais rodadas conseguiu-se concluir. Já em relação ao jogo computacional, como é composto por fases, os primeiros anos conseguiram concluir uma ou duas fases e assim, foram evoluindo a quantidade de fases finalizadas conforme a idade dos alunos. 


\section{Resultados e Discussões}

Durante o estudo de campo, realizou-se os 9 encontros sendo 3 de computação desplugada e 6 do jogo por meio de tablets que foram levados até a escola para uso individual das crianças. Ao todo, participaram 93 crianças, sendo 20 crianças de $1^{\circ}$ ano, 18 do $2^{\circ}$ ano, 14 do $3^{\circ}$ ano, 18 do $4^{\circ}$ ano e 23 do $5^{\circ}$ ano do ensino fundamental. As atividades ocorreram no mesmo turno que suas aulas acompanhadas pela professora regente da turma, durante um período de 45 minutos para cada encontro.

Em relação aos primeiros e segundos anos, identificou-se uma limitação inicial, pois elas não conseguiram compreender o que fazer nas atividades. Com o auxílio da explicação das professoras regentes, pôde-se dar continuidade as atividades, sendo parcialmente completadas por essas turmas. A partir de observação direta, percebeu-se que essas crianças por estarem ainda aprendendo conceitos básicos cognitivos, tinham o hábito de aprender replicando ao invés de aprender raciocinando efetivamente. Isso se mostrou devido a elas tentarem replicar a explicação em um cenário distinto do apresentado previamente, ainda na computação desplugada. Ao serem inseridas na atividade com o tablet, elas já se sentiram mais apropriadas do conhecimento e, embora as fases sejam diferenciadas, conseguiram superar as fases somente utilizando comandos de andar em alguma direção. Contudo, não conseguiam compreender muito bem como ir para a próxima fase, após finalizar a fase em questão. Em termos quantitativos, as crianças do primeiro ano conseguiram completar no máximo uma fase do cenário por encontro. Já as crianças do segundo ano conseguiram completar em média duas a três fases.

Em contrapartida, os alunos do $3^{\circ}$ ao $5^{\circ}$ ano se mostraram bem empenhados e conseguiram completar bem as atividades da computação desplugada, assim como do jogo. Em relação ao jogo, os alunos do $3^{\circ}$ ano conseguiram em média concluir 3 fases por encontro, os do $4^{\circ}$ ano entre 4 e 5 fases por encontro e os do $5^{\circ}$ ano mais que 5 fases, tendo alunos que concluíram 7 fases em um encontro. Desses, em média metade dos alunos do $5^{\circ}$ ano haviam realizado as atividades deste projeto de extensão em anos anteriores. Dessa forma, conseguiram avançar mais que os demais alunos, por já terem conhecimento prévio.

Partindo da premissa inicial levantada de que os exercícios que envolvem algoritmos influenciam positivamente no desenvolvimento do raciocínio lógico, comparou-se o algoritmo no papel solicitado no primeiro encontro com o mesmo algoritmo solicitado no último encontro. Lembrando que o algoritmo solicitado para os alunos escreverem foi "como o aluno sai de sua sala e chega até o refeitório".

Os algoritmos produzidos pelos alunos foram analisados individualmente e, para que houvesse um ponto de equilíbrio na avaliação, seguiu-se a seguinte classificação do algoritmo: Bem Detalhado (BD), para os algoritmos que detalharam todos os passos sendo possível chegar ao refeitório sem adicionar informação; Superficialmente Detalhado (SD), para os algoritmos que detalharam os passos, porém esqueceram pequenos pontos chaves que impediriam uma pessoa de chegar ao local caso não conhecesse o ambiente; Pouco Detalhado (PD), para os algoritmos que não realizaram todos os passos necessários, como por exemplo escrevendo somente "levanto da cadeira, vou até a escada e ando até o refeitório"; Fraco (F), para aqueles que escreveram pouquíssimas palavras, como por exemplo, "sigo a professora até o refeitório". Contudo, pôde-se realizar esta análise temporal somente para as turmas de $2^{\circ}$ e $5^{\circ}$ ano, sendo 11 alunos do segundo ano e 17 alunos do 
quinto ano, totalizando 28 alunos. As demais turmas não conseguiram concluir a atividade do algoritmo inicial por diversos fatores, sendo que realizaram apenas o algoritmo no último encontro.

No gráfico da Figura 7 tem-se uma visão geral da quantidade de alunos com cada uma dessas classificações após a correção da atividade do primeiro encontro e do último encontro. Realizando uma análise somente daqueles alunos que executaram a tarefa nos dois encontros, somente um aluno conseguiu ser classificado em uma escala superior ao pré teste, de modo que os demais permaneceram na mesma classificação.

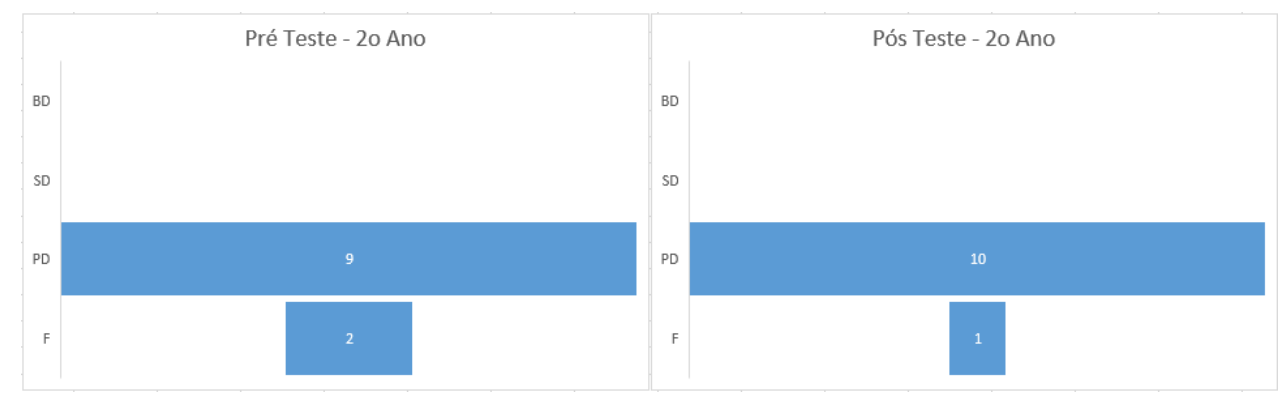

Figura 7. Comparação pré e pós teste do $2^{\circ}$ ano

Já em relação ao $5^{\circ}$ ano, nove dos 17 alunos foram classificados em uma escala superior ao primeiro encontro. Dos alunos que subiram o nível de classificação, somente um aluno do quinto ano melhorou seu algoritmo consideravelmente saindo da classificação PD para BD, representando dois níveis de melhoria. Os demais, subiram um nível apenas, sendo do PD para o SD, como é ilustrado no gráfico da Figura 8.

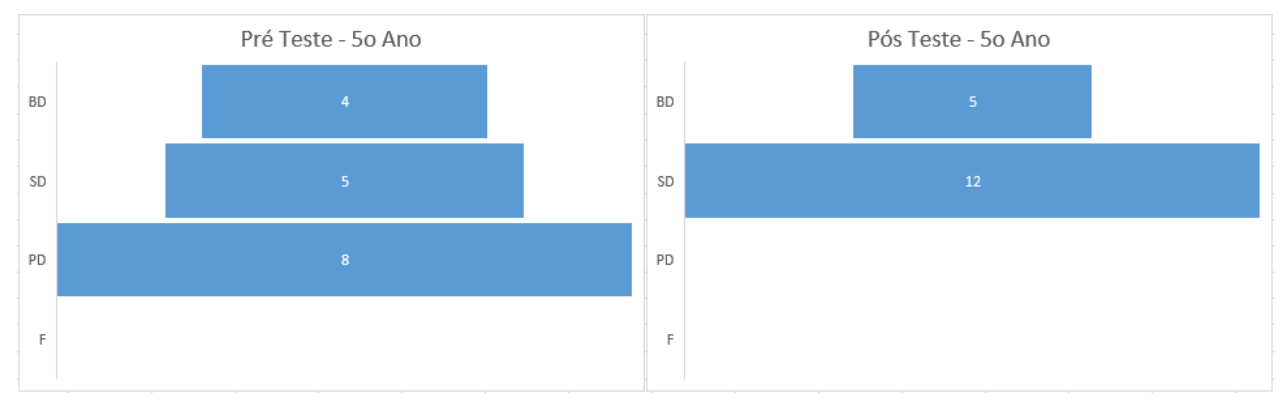

Figura 8. Comparação pré e pós teste do $5^{\circ}$ ano

Para aproveitar os dados produzidos pelos alunos do primeiro ao quinto ano gerados no último encontro, classificou-se os algoritmos finais produzidos. Com isso, obtevese as informações do gráfico da Figura 9. Neste, é possível visualizar as turmas de $1^{\circ}$ ao $5^{\circ}$ ano e a quantidade de alunos que obtiveram cada classificação após este último exercício. Observa-se que somente as turmas de $4^{\circ}$ e $5^{\circ}$ ano tiveram a classificação máxima de BD. Pode-se notar também à medida em que os anos vão passando, a classificação se tornou mais alta, mostrando que além da influência do jogo nessa classificação há também a influência de toda a aprendizagem adquirida nas demais disciplinas ao longo desses anos. A turma do $1^{\circ}$ ano chamou bastante atenção em seu resultado, tendo uma boa quantidade de SDs, mostrando que realmente evoluíram durante esses 9 encontros, uma vez que no primeiro encontro muitos nem sabiam escrever ainda e todos finalizaram o ano com essa conquista alcançada. 


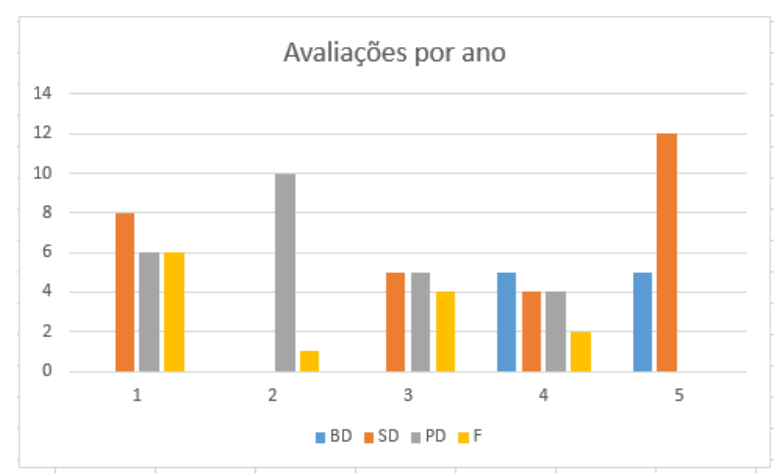

Figura 9. Relação das avaliações com os anos

\section{Conclusões}

Este trabalho apresentou a realização de um estudo de caso que durou 9 encontros de 45 minutos com cada uma das 5 turmas do $1^{\circ}$ ao $5^{\circ}$ ano de uma escola Estadual, sendo um total de 45 encontros com 93 alunos participantes. Nesses encontros foram realizadas atividades de pensamento computacional, utilização de computação desplugada e plugada com foco principal no pilar da construção de algoritmos.

Sendo a premissa inicial que os exercícios que envolvem algoritmos influenciam positivamente no desenvolvimento do raciocínio lógico, após a análise dos resultados é possível afirmar que eles influenciam, pois, comparando-se as turmas de $2^{\circ}$ e $5^{\circ}$ anos, observou-se um aumento na classificação de aproximadamente $9 \%$ dos alunos de $2^{\circ}$ ano e $52 \%$ dos alunos de $5^{\circ}$ ano em relação à primeira resolução. Contudo, não é possível identificar se somente o uso dessas atividades influencia no resultado, uma vez que os alunos continuaram seu ano escolar adquirindo conhecimentos das demais disciplinas e o teste não foi realizado com outros alunos que não tiveram contato com o jogo em questão.

Em relação ao objetivo deste trabalho de identificar se a prática com atividades mediadas por tecnologia móvel que utilizam recursos para estimular o desenvolvimento de habilidades em PC influenciam positivamente no processo de resolução de problemas cotidianos, pode-se afirmar que se observou algum grau de influência uma vez que na avaliação final das turmas, $51 \%$ das classificações dos problemas resolvidos são Bem Detalhados (BD) ou Superficialmente Detalhados (SD).

Como trabalhos futuros pretende-se aplicar esta mesma estratégia de avaliação em turmas que não fizeram uso de ferramentas de desenvolvimento de habilidades em PC e compará-las as que fizeram uso num mesmo espaço temporal a fim de verificar com maior precisão o grau de influência das tecnologias plugadas e desplugadas.

\section{Referências}

Avila, C., Cavalheiro, S., Bordini, A., Marques, M., Cardoso, M., e Feijo, G. (2017). Metodologias de avaliação do pensamento computacional: uma revisão sistemática. Brazilian Symposium on Computers in Education (Simpósio Brasileiro de Informática na Educação - SBIE), 28(1):113.

Brackmann, C. P. (2017). Desenvolvimento do Pensamento Computacional através de Atividades Desplugadas na Educação Básica. Tese de doutorado, PPGIE, UFRGS. 
Brasil (2017). Resolução cne/cp n ${ }^{0}$ 2, de 22 de dezembro de 2017. Institui e orienta a implantação da Base Nacional Comum Curricular, a ser respeitada obrigatoriamente ao longo das etapas e respectivas modalidades no âmbito da educação básica. Diário Oficial da União, Brasília, 22 de dezembro de 2017, Seção 1, pages 41-44.

CIEB (2018). Currículo de referência em tecnologia e computação. da Educação Infantil ao Ensino Fundamental. Centro de Inovação para a Educação Brasileira. São Paulo. p.104. http://curriculo.cieb.net.br/curriculo. Acessado em: jul. 2020.

Gil, A. C. (2002). Como Elaborar Projetos de Pesquisa. Atlas, São Paulo, fourth edition.

Kohler, L., Mattos, M., Zucco, F., Silveira, H., Fronza, L., Carlo, G., Santos, B., e Kohn, J. (2019). Circuito de quatro estações aplicando a computação desplugada. In Anais do XXV Workshop de Informática na Escola, pages 1369-1373, Porto Alegre, RS, Brasil. SBC.

Nunes, D. J. (2011). 12. ciência da computação na educação básica. http://jcnoticias.jornaldaciencia.org.br/ 12-ciencia-da-computacao-na-educacao-basica/. Acessado em: jul. 2020.

Raabe, A. L. A., Zorzo, A. F., Frango, I., Ribeiro, L., Granville, L. Z., Salgado, L., da Cruz, M. J. K., Bigolin, N., Cavalheiro, S. A. C., e Fortes, S. (2017). Referenciais de formação em computação: educação básica. SBC Editor. pages 1-9.

SBC (2019). Diretrizes para ensino de computação na educação básica. http://www.sbc.org.br/educacao/ diretrizes-para-ensino-de-computacao-na-educacao-basica. Acessado em: jul. 2020.

Stephenson, C., Cooper, S., Boucher Owens, B., e Gal-Ezer, J. (2012). The new csta k-12 computer science standards. In Proceedings of the 17th ACM Annual Conference on Innovation and Technology in Computer Science Education, ITiCSE '12, page 363-364, New York, NY, USA. Association for Computing Machinery.

Wazlawick, R. S. (2010). Uma reflexão sobre a pesquisa em ciência da computação à luz da classificação das ciências e do método científico. Revista de Sistemas de Informação da FSMA, 1(6):3-10.

Wing, J. M. (2006). Pensamento computacional. Commun. ACM, 49(3).

Zanetti, H., Borges, M., e Ricarte, I. (2016). Pensamento computacional no ensino de programação: Uma revisão sistemática da literatura brasileira. In Anais do XXVII Simpósio Brasileiro de Informática na Educação (SBIE 2016). Sociedade Brasileira de Computação - SBC. 